\title{
Surgically created double orifice repair of tricuspid regurgitation in infants with congenital heart disease
}

\author{
Toyoki Fukuda, MD, ${ }^{a}$ Ichiro Kashima, MD, and Shigeki Yoshiba, MD, ${ }^{\mathrm{b}}$ Tokyo, Japan
}

$\mathrm{R}$ epair of tricuspid regurgitation (TR) in infants with congenital heart disease (CHD) is frequently associated with postoperative morbidity. Annuloplasty is a well-established surgical procedure for TR and is associated with a satisfactory postoperative outcome provided the deformity of the tricuspid leaflet is mild. However, in the presence of severe leaflet deformity, the reparative procedure remains a surgical challenge. The present study describes our experience with the surgically created double orifice repair of the tricuspid valve in infants with CHD and significant TR.

\section{Clinical Summary}

PATIENT 1. A 7-month-old male infant was referred to our hospital at 1 month of age with the diagnosis of double outlet from the right ventricle, pulmonary hypertension, TR, and bronchial stenosis. At 2 months of age, the clinical condition deteriorated progressively due to respiratory tract infection. Although he underwent pulmonary artery banding (PAB) at 3 months of age, weaning from the respirator was unsuccessful. At 7 months of age, he underwent a definitive operation, in which intraventricular rerouting was established with a 0.4-mm Gore-Tex patch (W. L. Gore \& Associates, Inc, Flagstaff, Ariz) connecting the left ventricle with the aorta. The tricuspid valve was dilated to $23 \mathrm{~mm}$ and showed a diffuse degenerative change with deficient valvar tissue near the commissure between the anterior and septal leaflet (Figure 1, B). Because Reed's annuloplasty at this area failed to alleviate TR, a double orifice repair was performed wherein the central free edge of the anterior leaflet was approximated to the facing edge of the septal leaflet with a 5-0 polypropylene mattress suture (Figure $1, C$ ). The divided orifices were equal in size, each measuring $10 \mathrm{~mm}$. The patient recovered uneventfully and was weaned from the respirator on postoperative day 5 . The mean right atrial pressure ranged from 5 to $9 \mathrm{~mm} \mathrm{Hg}$ in early postoperative days and was $3 \mathrm{~mm} \mathrm{Hg}$ at 6 months after surgery. Postoperative Doppler echocardiography demonstrated a divided unobstructed flow through the tricuspid

From the Division of Cardiovascular Surgery ${ }^{\mathrm{a}}$ and Pediatric Cardiology, Tokyo Metropolitan Kiyose Children's Hospital, Tokyo, Japan.

Received for publication Jan 28, 2003; accepted for publication March 11, 2003.

Address for reprints: Toyoki Fukuda, MD, Division of Cardiovascular Surgery, Tokyo Metropolitan Kiyose Children's Hospital, 1-3-1 Umezono, Kiyose-shi, Tokyo 204-8567, Japan (E-mail: fukuda@chp-kiyosetokyo.jp).

J Thorac Cardiovasc Surg 2003;126:1220-1

Copyright (C) 2003 by The American Association for Thoracic Surgery $0022-5223 / 2003 \$ 30.00+0$

doi:10.1016/S0022-5223(03)00786-4 valve (Figure 1, A) and trivial TR. At the last follow-up 10 months after surgery, the patient was doing well without the need for medication.

PATIENT 2. An 11-month-old female infant was admitted on the day of birth due to tachypnea, heart murmur, and hypotension. Cross-sectional and Doppler echocardiography demonstrated a perimembranous ventricular septal defect and significant TR. She underwent PAB at 2 months of age. Catheter examination at 7 months of age demonstrated high blood flow in pulmonary arteries, pulmonary hypertension, and a tricuspid valve pouch protruding toward the right atrium (Figure 2, A). At 11 months of age, she underwent patch closure of the defect and repair of TR. Tricuspid annulus was dilated to $22 \mathrm{~mm}$, and the anterior leaflet showed a peculiar deformity with a saccular pouch protruding toward the right atrium (Figure 2, B). Because Reed's annuloplasty failed to alleviate TR, a modified double orifice repair was performed wherein the tip of the pouch was anchored to the facing edge of the septal leaflet with a 5-0 polypropylene mattress suture (Figure 2, $C)$. The medial and lateral orifices measured 10 and $7 \mathrm{~mm}$, respectively. The mean postoperative pressure of the right atrium ranged from 5 to $10 \mathrm{~mm} \mathrm{Hg}$. Doppler echocardiography showed an unobstructed flow through the tricuspid valve and mild TR. The patient is currently doing well and is on digoxin and diuretics.

\section{Comments}

Repair of TR in infants with CHD could be associated with serious postoperative complications. Although the majority of TR is amenable with the currently available annuloplasty, severe deformity of the valvar leaflet represents a challenge for repair. The double orifice repair of the atrioventricular valve was first reported by Fucci and associates ${ }^{1}$ and documented later by Maisano and associates $^{2,3}$ as a promising valve-sparing procedure in adults. More recently, Macé and associates ${ }^{4}$ applied this procedure to infants with favorable results. In addition, although this method was primarily developed for the repair of mitral regurgitation, recent studies suggest that it is equally effective for TR. ${ }^{5}$ Inasmuch as this technique is simple and less time-consuming, it is of great advantage for infants who require repair of complex CHD.

Various techniques have been proposed as the approximating procedure of the afflicted leaflet. ${ }^{2,4,5}$ Although a satisfactory result was obtained from unsupported mattress suture, pledget-supported suture may be a preferable choice to the thin leaflet. ${ }^{4}$

In conclusion, the double orifice repair of the tricuspid valve is a promising valve-sparing procedure for infants with degenerative changes of the tricuspid leaflet and severe TR, although the longterm result including the potential growth of the divided orifice is yet to be seen. 

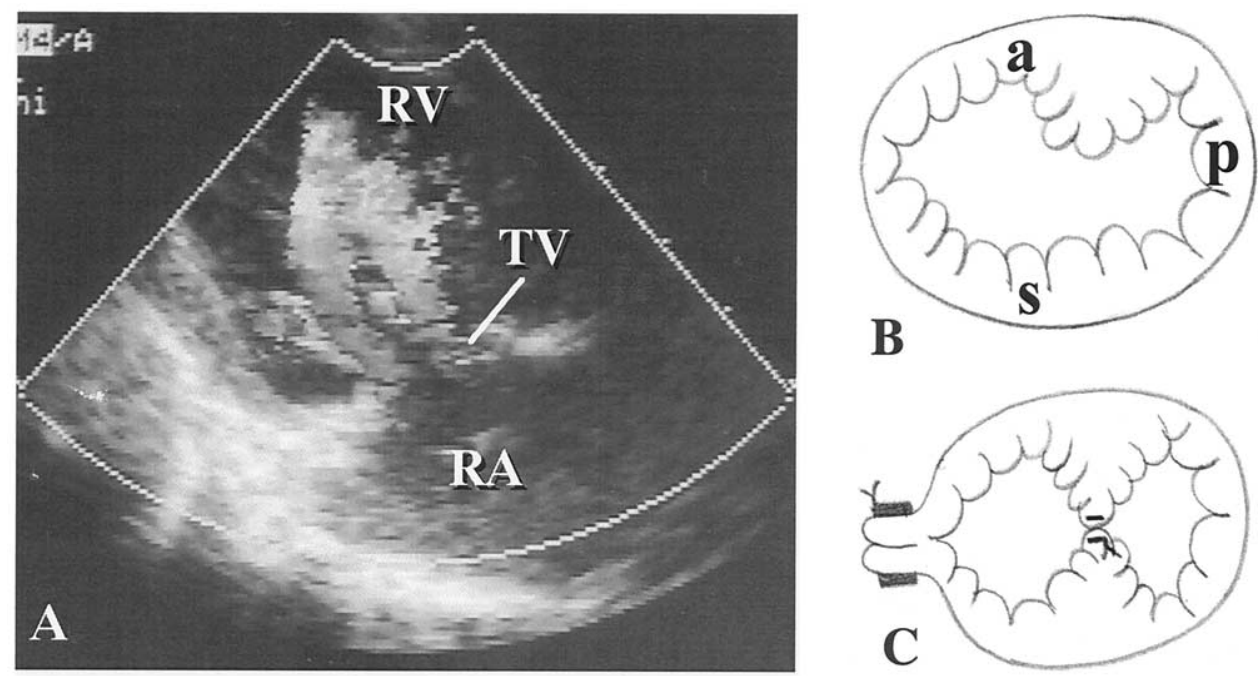

Figure 1. Patient 1. A, Apical 2-cavity long-axis view of postoperative echocardiography. Diastolic color-coded flow demonstrated a divided unobstructed flow through the tricuspid valve. B, Surgeon's view of the tricuspid valve showed degenerative changes of the leaflet and annular dilation. C, Repair included Reed's annuloplasty and double orifice repair. $R A$, Right atrium; $R V$, right ventricle; $T V$, tricuspid valve; a, anterior leaflet; s, septal leaflet; p, posterior leaflet.
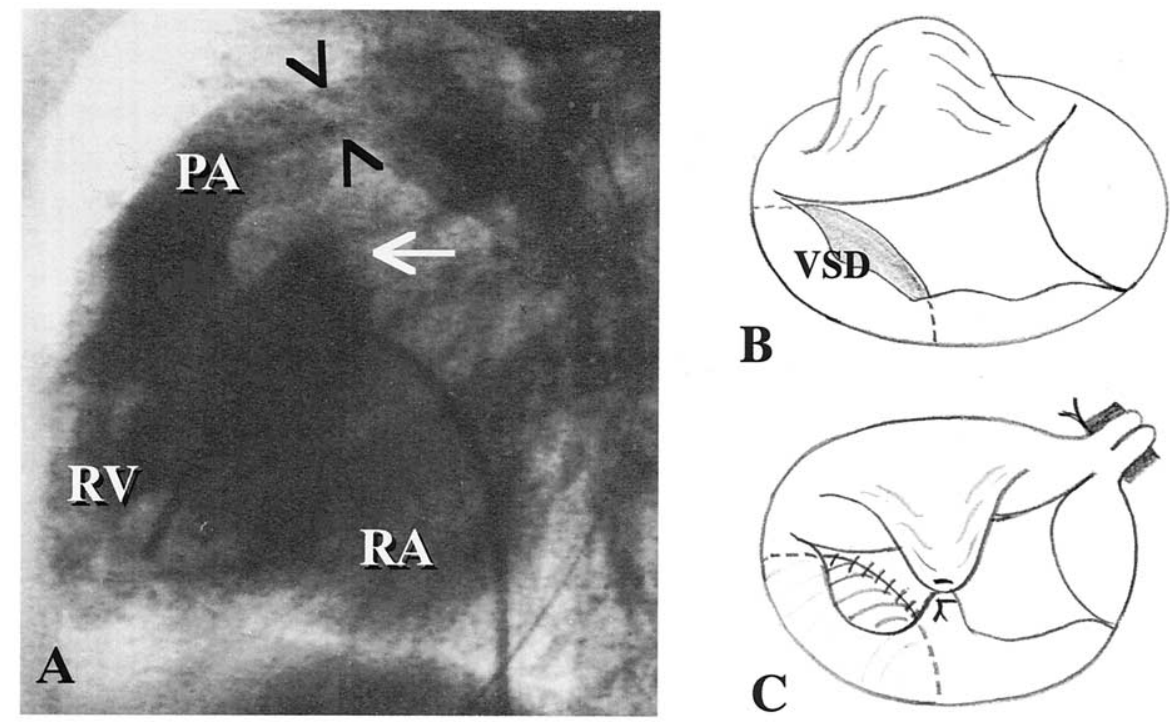

Figure 2. Patient 2. A, Right ventriculography of patient 2 after pulmonary artery banding (arrowheads). The lateral projection showed moderate tricuspid regurgitation and tricuspid valve pouch (arrow) protruding toward the right atrium. B, Surgeon's view demonstrated a saccular pouch of the anterior leaflet of the tricuspid valve. C, Repair included Reed's annuloplasty and modified double orifice repair. VSD, Ventricular septal defect. Other abbreviations as in Figure 1.

\section{References}

1. Fucci C, Sandrelli L, Pardini A, Torracca L, Ferrari M, Alfieri O. Improved results with mitral valve repair using new surgical techniques. Eur J Cardiovasc Surg. 1995;9:621-6.

2. Maisano F, Torrecca L, Oppizzi M, et al. The edge-to-edge technique: a simplified method to correct mitral insufficiency. Eur J Cardiovasc Surg. 1998;13:240-6.
3. Alfieri O, Maisano F, De Bonis M, et al. The double-orifice technique in mitral valve repair: a simple solution for complex problems. $J$ Thorac Cardiovasc Surg. 2001;122:674-81.

4. Macé L, Dervanian P, Houyel L, et al. Surgically created double-orifice left atrioventricular valve: a valve-sparing repair in selected atrioventricular septal defects. J Thorac Cardiovasc Surg. 2001;121:352-65.

5. Maisano F, Lorusso R, Sandrelli L, et al. Valve repair for traumatic tricuspid regurgitation. Eur J Cardiovasc Surg. 1996;10:867-73. 